\title{
The Informing Sciences at a Crossroads: The Role of the Client
}

\author{
Grandon Gill and Anol Bhattacherjee \\ University of South Florida, Tampa, Florida, USA
}

\author{
ggill@coba.usf.edu abhatt@coba.usf.edu
}

\begin{abstract}
The essential elements of an informing system are a sender, a communications pathway, and a client. Academic informing systems, however, are best viewed as two interacting informing systems, one that informs clients of a discipline, one that informs clients of the institution. The paper proposes that the greater the degree of overlap between the clients of these two systems, the stronger the position of an individual discipline is likely to be.

MIS is presented as an example of a disciplinary informing system that has ceased to inform external clients. This situation, it is argued, is likely to result in the discipline's downfall. The informing sciences transdiscipline itself is then examined using the same lens. While much younger than MIS, the paper argues that informing sciences needs to begin its search for clients in earnest. Building upon lessons learned from another transdiscipline, complex systems, a series of concrete recommendations are presented.
\end{abstract}

Keywords: informing sciences, informing systems, client, sender, MIS, institutional priorities, transdiscipline.

\section{Introduction}

The Informing Sciences have made remarkable strides as a transdiscipline over the past decade. Its flagship journal, Informing Science, has gained international recognition and has been steadily moving up the management information systems (MIS) journal rankings. The Informing Science Institute (ISI), its umbrella organization, has launched numerous innovative and successful journals, is becoming an active publisher of scholarly monographs and sponsors the highly successful InSITE international conference at a period in time when many conferences, especially in the MIS area, see their attendance dwindling.

In the midst of celebrating these accomplishments, we would do well to sound a cautionary note. Other disciplines have raised expectations and subsequently failed to deliver on their promises. Indeed, the core of the rationale for establishing the informing sciences as a transdiscipline was

Material published as part of this publication, either on-line or in print, is copyrighted by the Informing Science Institute. Permission to make digital or paper copy of part or all of these works for personal or classroom use is granted without fee provided that the copies are not made or distributed for profit or commercial advantage AND that copies 1) bear this notice in full and 2) give the full citation on the first page. It is permissible to abstract these works so long as credit is given. To copy in all other cases or to republish or to post on a server or to redistribute to lists requires specific permission and payment of a fee. Contact Publisher@InformingScience.org to request redistribution permission. serious shortcomings in the MIS discipline (Cohen, 1999). The very real danger is that the informing sciences may well fall victim to a similar set of shortcomings, then vanish into obscurity.

Many reasons have been postulated as to why disciplines succeed and fail. In the case of MIS, these reasons include lack of focus (Cohen, 1999; Benbasat \& Zmud, 2003), the need for a broader macro focus (Agarwal \& Lucas, 2005), 
lack of relevance (Benbasat \& Zmud, 1999), lack of rigor in some of its qualitative research practices (Dubé \& Paré, 2003), the need for more meaningful theory (Gregor, 2006), and too much emphasis on cumulative research tradition as opposed to more professionally focused research (Davenport \& Markus, 2003). The very diversity of these diagnoses implies that -while there is a strong suspicion that a crisis exists in the MIS field (Agarwal \& Lucas, 2005) - the underlying cause of the crisis remains speculative.

We believe that a better way to explain the success and failure of an academic discipline is to view it as an informing system. In this paper, we begin by presenting an overview of the informing systems framework, as introduced in Cohen's (1999) seminal paper. We then present, as a case study example, an analysis of the MIS discipline using the framework. The results of this analysis highlight the critical, and often overlooked, role played by external clients in disciplinary informing systems. Finally, discuss the implications of these findings for informing sciences, and the types of steps that must be taken if the transdiscipline is to continue making meaningful contributions to the world's knowledge.

\section{Informing Science Framework: An Overview}

The informing science discipline emerged as a result of the observation that many disciplines, including MIS, education, library science, computer science and others, were studying the movement of information between senders and receivers in ways that were far more similar than they were different. In the seminal article that launched the discipline, Cohen (1999) defined the transdiscipline as follows:

The fields that comprise the discipline of Informing Science provide their clientele with information in a form, format, and schedule that maximizes its effectiveness.

Cohen further defines three underlying precepts of informing science:

1. A framework for characterizing such systems that involves a sender, a communications pathway and a receiver. These are described as the informing environment, the delivery system and the task completion environment.

2. The ability to characterize such systems at many levels. Three such levels include the level at which actual informing occurs, the level at which new informing instances are created, and the level at which overall designs for such systems are specified.

3. The inherent inter-relatedness of the components of such systems: task, technology, structure and people.

Each of these precepts is now explored briefly.

\section{Informing Framework}

Cohen (1999) uses Shannon's (Shannon \& Weaver, 1949) communications model (sender, encoder, medium, decoder and receiver) as the principal lens through which informing systems are viewed. A simplified version of that model is presented in Figure 1.

In practical situations, such a simple model rarely suffices. Many factors make "real world" inform-

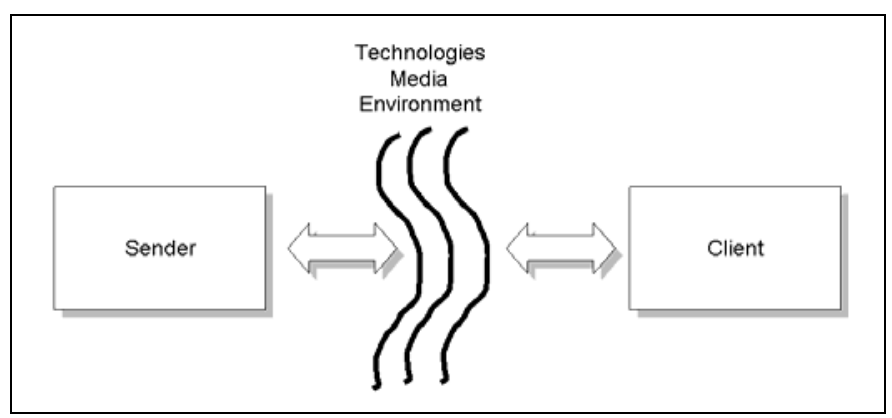

Figure 1: Basic Informing System Model 
ing systems much more complex. Examples of these include:

1. Sender and client components are rarely homogeneous. Rather, senders consist of complex informing environments that involve subsystems that may, themselves, be informing systems. The same can be said of clients, described by Cohen (1999) as task completion systems.

2. Senders may be members of multiple informing systems that inform different clients. Drucker (1989), for example, refers to the inherent tension that knowledge workers experience as they divide their loyalties between profession (e.g., accounting, law, medicine) and the organization that employs them.

3. Multiple senders may compete to inform the same client. For example different departments (disciplines) may compete for the same set of students; doctors from different specialties may compete to diagnose the same patients, etc.

4. Multiple communications pathways may be utilized within the same informing system. For example, an advertising campaign may involve the use of print, broadcast and webbased media in order to reach its entire client base.

5. Multiple clients may be informed by the same sender, and may have to compete for that sender's attention. For example, a patient may find his or her case is neglected as a consequence of the attention a doctor pays to the needs of other patients.

6. Clients may, themselves, serve as part of an extended informing system. For example, a company may depend heavily on "word of mouth" advertising to gain new clients.

The types of complexities these factors can add to a system are illustrated in Figure 2.

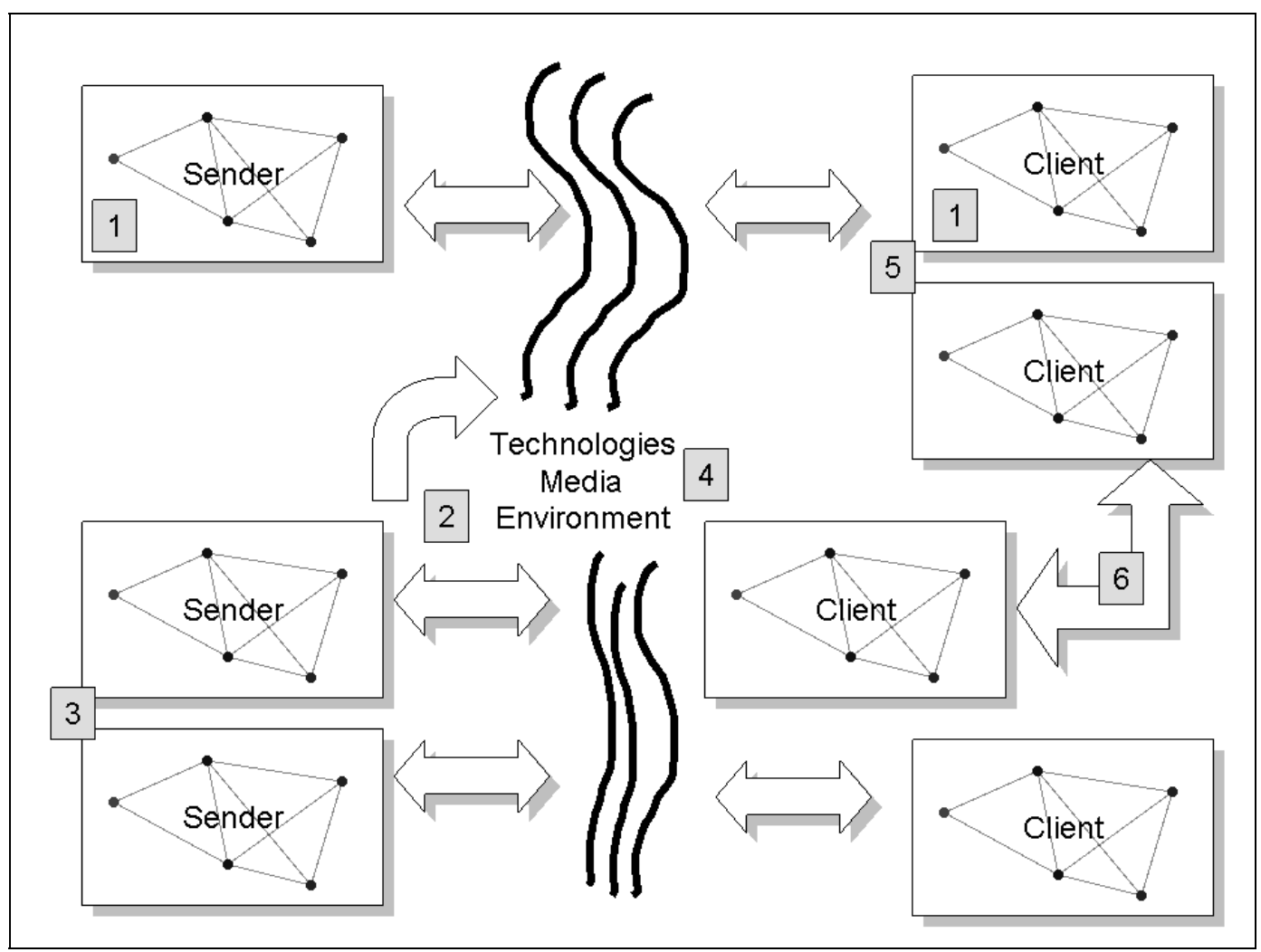

Figure 2: Complexities in "real world" informing systems 


\section{Levels of Abstraction}

A second precept of informing science is that systems can be examined at multiple levels of abstraction. Cohen (1999) lists three specifically: the informing instance itself, the system responsible for constructing new informing instances and, finally, the system that designs new types of informing systems. He presents two examples. The academic example: teaching a course designed by others (instance), creating a new course (constructing), and designing anew curriculum (design). The business example: using an existing transaction processing system (TPS; instance), building a new TPS from existing rules (constructing) and creating a new type of TPS (design).

From these examples, we see that these different levels of abstraction may also correspond to different levels or areas of the informing system where the organization is housed. We may also conclude that the boundaries of informing system levels are somewhat permeable. For example, redesigning an existing course and designing a new course obviously represent part of a continuum between instance and design.

\section{Interrelatedness}

A final precept of informing science is that the elements of an informing system (e.g., task, technology, structure and people) interact in a manner that is sufficiently complex such that changing the characteristics of one component (e.g., technology) can have a significant impact on the behavior of other components (Cohen, 1999). Systems with such characteristics tend to resist decomposition (Simon, 1981), meaning that behavior is best examined at the system level, since understanding individual component behaviors does not necessarily lead to a valid picture of how the system as a whole will behave-indeed, such is essentially how Simon defines system complexity.

An important implication of this interrelatedness is that technology must play a particularly central role in informing science research, since it tends to be the element within such systems that is changing most rapidly, and is therefore the engine that drives much of the change in system behavior. A further implication of interrelatedness and technology's role is that informing science research must, of necessity, proceed at a rapid pace, since technology-induced changes to system behavior will tend to occur continuously. Should the time between observation and dissemination of such research be too great, the behaviors being observed will likely cease to be relevant.

\section{An Informing Science Case Study: The MIS Discipline}

The MIS field has always played a pivotal role in informing science. Much of the motivation for establishing the informing science transdiscipline came from observed weaknesses in MIS (Cohen, 1999). Equally important, many of the participants in informing science are also participants in the MIS discipline, where the journal Informing Science Journal has been ranked (Pfeffers \& Tang, 2003). Finally, there is considerable overlap between the management-technology focus of MIS and the informing science framework. Indeed, the latter can be viewed as a powerful lens through which to view the former.

\section{The Current Situation in MIS}

As previously noted in the introduction, there is a strong contingent within the MIS research community who believe that the discipline is in crisis (Agarwal \& Lucas, 2005). Such concerns are not new. Cohen (1999) observed found that field was not well differentiated from applied computer science, fragmented in its research (citing Swanson \& Ramiller, 1993) and teaching (citing Davis, Gorgone, Couger, Feinstein, \& Logenecker, 1997), and taught material that was also being presented in other disciplines (citing Cohen, 1997). Additional critiques have decried the field's pursuit of rigor over relevance (e.g., Benbasat \& Zmud, 1999; Davenport \& Markus, 
1999), but have differed widely in their prescriptions - ranging from the need to develop more "cumulative theory-based, context rich" research (e.g., Benbasat \& Zmud, 1999) to moving the discipline's emphasis towards practice-focused disciplines, such as law (e.g., Davenport \& Markus, 1999). Moreover, concerns regarding the need for greater rigor in MIS case studies (which tend to be, presumably, high on the relevance scale) have also been raised (e.g., Dubé \& Paré, 2003).

Although the existence of an "MIS research crisis" is still far from universally accepted, what is recognized by virtually everyone is the fact that enrollments in MIS programs have dropped substantially. Some institutions with large undergraduate programs (e.g., Georgia State University, University of South Florida, Florida Atlantic University) — each having MIS major enrollments in excess of 700 students at their peak - have reported declines in the $70-80 \%$ range since 2001. Moreover, these declines have persisted despite that fact that the decline in the IT workforce that began during the heyday for MIS enrollments actually began rebounding in 2003, based on U.S. Bureau of Labor Statistics data (http://www.bls.gov/OES/) and, by 2005, had exceeded its year 2000 peak. The impact of this is now becoming of grave concern for future MIS doctoral students. As it stands, absent unusually high demand for faculty - such as that caused by the rapid build up of enrollments that occurred in the later $1990 \mathrm{~s}$ - only about $5 \%$ of all MIS doctoral students are predicted to be able to achieve the research standards of research extensive and elite universities (Dennis, Valacich, Fuller, \& Schneider, 2006). Barring another jump in enrollments (that would serve to motivate a relaxation of these standards), the prospects of the untenured IS faculty member would seem to be grim indeed.

It can, of course, be argued that these depressing prognostications ignore the history of the MIS academic discipline. After all, a similar (although much less severe) drought in MIS academic hiring occurred in the early 1990s. And, scarcely half a decade ago, the great fear was that a permanent shortage of MIS faculty would exist (Freeman, Jarvenpaa, \& Wheeler, 2000). The fundamental question therefore becomes: Is MIS experiencing just another in a long series of fluctuations, or is this the beginning of the death spiral of the discipline? To answer this question, simply projecting current trends is likely to prove woefully inadequate-as, indeed, it has in the past. We believe that a much more effective approach involves looking at the MIS discipline as an informing system.

\section{The Academic Informing Systems}

Unlike some research disciplines - such as engineering and medicine, where research advances can occur in many settings (e.g., in industry, hospitals, government-sponsored laboratories) - the MIS discipline is housed nearly entirely in academic institutions, mainly universities. For this reason, the disciplinary informing system needs to be studied as it relates to the institutional informing system, which supplies most of its resources (e.g., salaries, research support, facilities). Furthermore, as was noted in the earlier introduction to informing systems, these systems exist at three levels - two of which involve participants that share two roles. For the disciplinary informing system, the instance role is played by the faculty member, who conducts research and writes papers according to the guidelines of the discipline (at least if he or she wishes to be published). At the construction level, there is the department - responsible for creating new informing instances (i.e., doctoral students who become faculty) and for setting hiring priorities that help determine the research direction of the department. At the creation level, there are the journals and eminent scholars of the field, whose recommendations essentially define where the field will go, through editoral policy, willingness to co-author, external reviews of promotion and tenure candidates and through setting the agenda for disciplinary conferences. For the institutional informing system, supplying resources to the disciplinary informing system helps to satisfy its research mission. More important, however, faculty members - in their teaching capacity — are also funda- 
mental elements of the instance level of the informing system for which students are the client, and departments, in their administrative capacity, serve both to organize faculty (through teaching assignments) and to create new course and program instances. Only at the creation level do the participants in the institutional informing system (e.g., university leadership, trustees) and the disciplinary informing system (e.g., journal editors, eminent scholars) diverge substantially.

Another source of complexity in academic informing systems is that multiple clients exist for both disciplinary and institutional systems. For disciplinary informing systems, whose principal activity is research, these clients are served by three types of research:

- Pure research: Research that is principally aimed at internal clients, that is to say, clients within the discipline itself. Such research is an essential part of a discipline's ability to advance since - at least in theory - it represents a form of organizational learning through changing the theory-in-use over time (Gill, 1995).

- Applied research: Research that is directed towards other clients. Among these are included practitioners, interested members of the public or other disciplines (e.g., applied mathematics describes the use of mathematical techniques in physics, chemistry, economics, etc.)

- Scholarship of teaching (SOT) and ancillary research: Research that is specifically directed towards improving the effectiveness of teaching (i.e., informing student clients) or other aspects of the discipline. It makes sense to distinguish SOT/ancillary research from other forms of applied research because it can easily draw upon an entirely different set of reference disciplines (e.g., psychology, education) than those of the discipline itself (e.g., engineering, science, fine arts, etc.)

These research categories (along with a fourth, unrelated research) are illustrated in Figure 3, which presents two dimensions: external-internal clients, and disciplinary-other paradigms used to conduct the research.

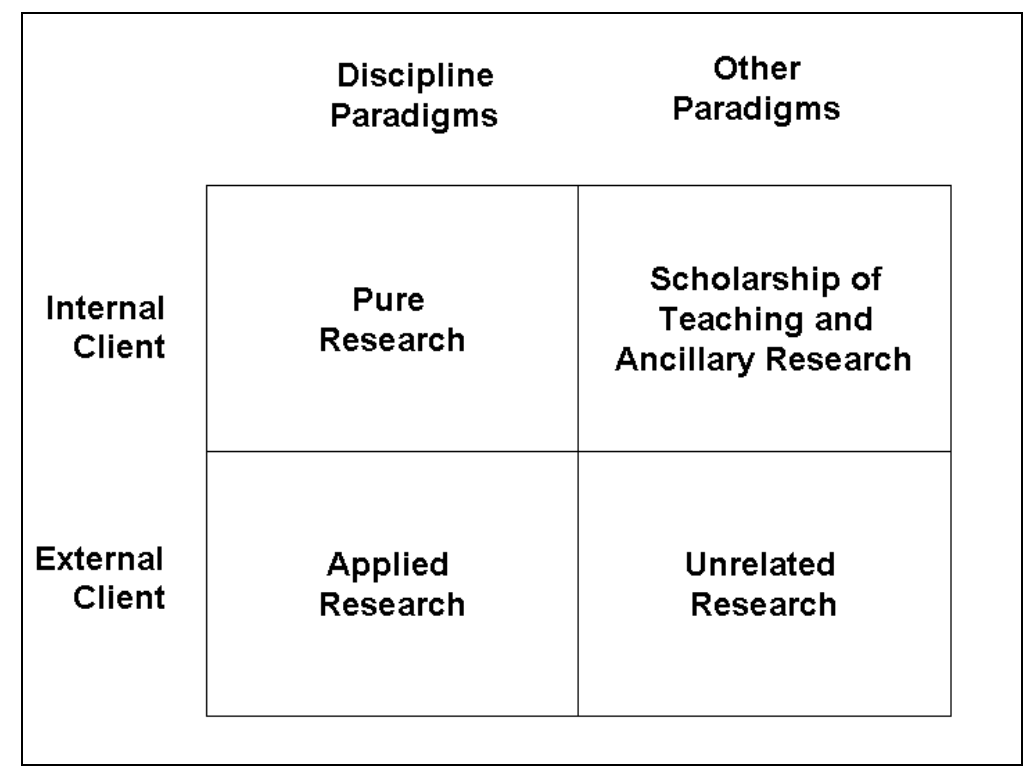

Figure 3: Categories of research

Institutional clients, on the other hand, involve many different constituencies (Trieschmann, Dennis, Northcraft, \& Niemi, 2000), which could include students, regulators, employers, benefactors, community leaders, accreditation organizations, ranking organizations, and others. Only a 
small number of these may overlap a discipline's clients (e.g., students, practitioners/employers, granting agencies, etc.) These relationships are illustrated in Figure 4.

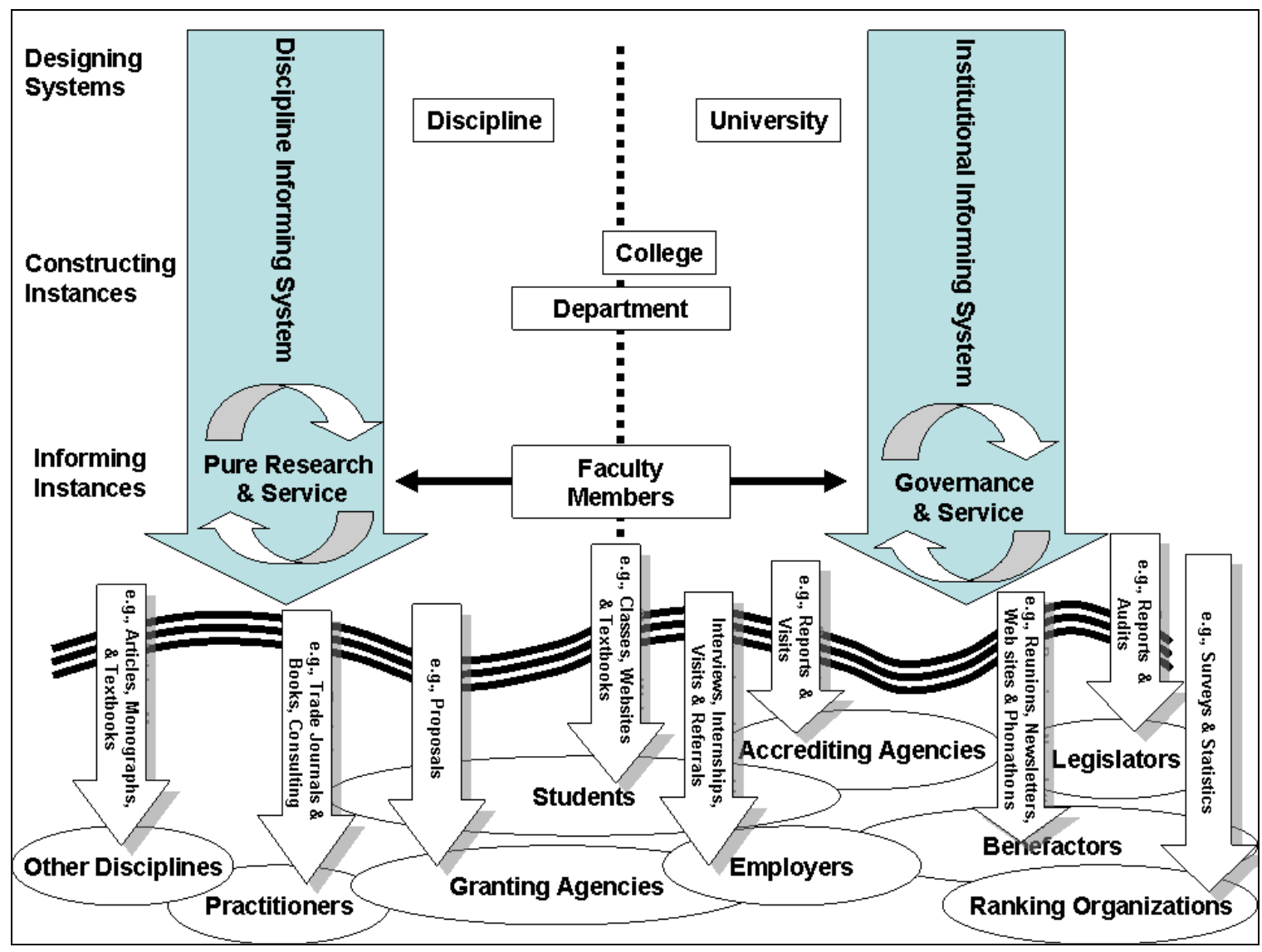

Figure 4: Disciplinary and Institutional Informing Systems

As suggested by the dotted line down the middle of the diagram, participants in both informing environments (e.g., colleges, departments, faculty members) face choices regarding how to allocate their activities between systems. All other things being equal, it is reasonable to suppose that such allocation will, to a great extent, be determined by how it impacts the participant's access to resources. For the individual faculty member with an active research program, this pull is likely to be in the direction of maximizing disciplinary participation. For department/college participants, on the other hand, the greatest return is likely to come from activities that impact position in the institution's resource queue. They are therefore likely to gravitate towards increased institutional participation.

The paired informing system perspective also suggests that the degree of overlap between a discipline's clients and the clients of a specific institution is likely to have a profound effect on how well that particular discipline thrives within the institution. The reasoning here is as follows. Although disciplinary informing systems tend to be largely self-regulating, most (with engineering and medicine being notable exceptions) tend to be nearly entirely dependent upon the institutional informing system for resources. Thus, it will ultimately be the institution that determines the percentage of available resources that are allocated to each discipline's activities. Assuming any type of rational budgeting approach is utilized, a key component of the decision will be the degree to which each marginal dollar allocated to a discipline yields marginal gains amongst the institution's various client constituencies. It should be noted that such a calculation would not normally involve the intra-disciplinary research contributions of the faculty-except to the degree to which 
they impact the institution's clients (e.g., the department's pure research activities might be bringing in substantial grants with associated institutional overhead components; a strong research reputation in a particular department might lead to a higher overall ranking of the university in U.S. News and World Report; reducing funding to a particular department might impact an institution's accreditation status).

\section{The MIS Informing System}

When viewing MIS as an informing system, our first question becomes: Who are the external clients? As a discipline allied with business research, there are two clients we would invariably expect to find: practitioners and students. Thus we ask: how well is the discipline informing these clients?

There has been considerable debate regarding the degree to which MIS research is actually informing practitioner clients. The two sides of the debate, however, do not appear to cover the full spectrum of possible opinions. Instead, opinions range from "the business community would question the relevance of IS research as published in the leading journals of our field" (Benbasat \& Zmud, 1999) to "the extent to which IS research is relevant to IS practice is, objectively speaking, unknown" (Lee, 1999). Moreover, there is also disagreement as to the pathway through which the discipline should inform its practitioner clients-going directly to senior practitioners or informing through students (Davenport \& Markus, 1999), with textbooks playing an important role (Lyytinen, 1999). What can be observed empirically, however, is that practitioner participation in MIS research - at least in the form of collaborative authorships and contributions to the discipline's premier journal (MIS Quarterly) - has fallen precipitously over the past quarter century, from $41 \%$ (in 1980) to $0 \%$ (in 2005), as shown in Table 1.

Table 1: Industry and academic author contributions to MISQ at 5 year intervals

\begin{tabular}{|c|c|c|c|c|c|}
\hline Year & $\begin{array}{l}\text { Count of } \\
\text { Articles }\end{array}$ & $\begin{array}{c}\text { Academic } \\
\text { Authors }\end{array}$ & $\begin{array}{l}\text { Industry } \\
\text { Authors }\end{array}$ & $\begin{array}{l}\text { Total } \\
\text { Authors }\end{array}$ & $\begin{array}{l}\text { Percent of } \\
\text { Authors from } \\
\text { Industry }\end{array}$ \\
\hline 1980 & 18 & 16 & 11 & 27 & $41 \%$ \\
\hline 1985 & 23 & 32 & 8 & 40 & $20 \%$ \\
\hline 1990 & 23 & 45 & 11 & 56 & $20 \%$ \\
\hline 1995 & 24 & 60 & 3 & 63 & $5 \%$ \\
\hline 2000 & 23 & 55 & 3 & 58 & $5 \%$ \\
\hline 2005 & 28 & 66 & 0 & 66 & $0 \%$ \\
\hline
\end{tabular}

Anecdotal observations seem to confirm the patterns observed in the table. For instance, the Society for Information Management (principally a practitioner group) chose to stop supplying its members with free subscriptions to MIS Quarterly in 1995, at which point most members dropped their subscription (Benbasat \& Zmud, 1999). Further evidence of the lack of priority placed on the practitioner client is the fact that practitioner-focused journals tend to be rated well below academic journals in IS journal rankings. For example, on the comprehensive AIS ranking list (posted at http://www.isworld.org/csaunders/rankings.htm), Harvard Business Review tops the list at $8^{\text {th }}$ place, followed by Sloan Management Review at $19^{\text {th }}$ place and California Management Review at $43^{\text {rd }}$ place. The significance of these placements is underscored by the fact that "elite" journal status in MIS is normally reserved for the top two finishers and that a third contender, Communications of the ACM, dropped out of contention after "having shifted its focus to applied, practitioner-focused articles" (Dennis et al., 2006). There are also examples of situations where MIS-related issues are addressed in the practitioner community without any considering any of the findings of the academic research discipline. For example, a recent report prepared by 
the U.K. National Audit Office (2006) focused on delivering "successful IT-enabled business change" - an area clearly central to MIS research — without making a single reference to MIS disciplinary research findings.

Taken together, these observations strongly suggest that the MIS disciplinary informing system supports very limited pathways, at best, from its sender side (researchers) to its practitioner clients. Although the weak academic-practitioner linkage has long been recognized by the discipline-with its frequent calls for increased relevance-it is not clear what purpose relevance would serve given that the informing system does not currently place a premium on the communications linkages that would ensure strong researcher-to-practitioner information flow. If it did, the field would tend to place a higher value on publishing in practitioner journals, on writing the types of books that one sees in airport gift shops, and upon engaging in consulting activities (many of which are applauded, or at least tolerated, by other business disciplines such as management). It could be argued, of course, that the reason for such a trend is that the MIS discipline has matured and became more theoretical, scientific, more methodologically (and even mathematically) sophisticated and demanding - all of these making it less accessible to managers. But this is just another way of saying that the discipline has chosen to focus on informing itself, rather than on placing a priority on informing activities that meet the needs of the practitioner client.

The second natural client for the MIS discipline is its students. In its early years, the discipline was blessed with ever-increasing enrollments that it could have easily attributed to its own efforts. These increases reached a crescendo around the time of the millennium, when massive faculty shortages - created by annual double-digit increases in MIS program enrollments - were being experienced throughout the U.S. With the bursting of the Internet-bubble and the information technology (IT) industry slowdown that accompanied the successful avoidance of a Y2K disaster, the situation changed radically. Although we know of no authoritative source that yet identifies the full magnitude of the downturn (educational statistics lag by several years), anecdotal surveys of faculty conducted at conferences and in other settings suggest that few programs experienced downturns of less than 50\% from their peak (George, Valacich, \& Valor, 2004) and that manyespecially at larger institutions where students had many alternative majors to choose fromexperienced declines as high as $80 \%$. Since it is doubtful the field is entirely to blame for the crash in enrollments, it is equally reasonable to question whatever credit it took for the prior rise.

To assess the degree to which the MIS informing system serves its student clients, we attempted to compare the level at which research interests (clearly central to the informing system) overlap teaching interests. To do so, we took the AIS database - containing a comprehensive listing of nearly all MIS faculty members - and did a comparison of research interests with teaching areas. The following procedure was employed:

- Four teaching areas were selected as being fundamental to an MIS core curriculum: programming, systems analysis and design, data communications, and databases. We specifically chose to omit other candidates (e.g., the MIS survey course) because it would be too difficult to assess what research was, and was not, relevant to such teaching.

- The research interests specified by the individual faculty members (4468 topics in all) were individually ranked for relevance to the teaching area on a scale of directly relevant, indirectly relevant, and not relevant. Both authors conducted this ranking independently, the results were then compared, with 3615 (76.5\%) agreeing and 853 $(23.5 \%)$ disagreeing (approximately $2 / 3$ of all disagreements occurred when one author rated a topic as directly related to a teaching area, while the other rated it as being indirectly related). Together, the authors then jointly rated the differing areas, further classifying the nature of the resolution as being consensus (100\%) or coin toss $(0 \%)$. 
- The research interests were then compared with the teaching interests across all faculty members teaching in the specified area, with each faculty member being identified as having no match, indirect match or direct match between teaching area and research area. A query looking for any type of match was also conducted.

- A subset of the faculty was prepared, those from 44 highly ranked MIS research institutions by virtue of elite journal publications, created by merging two lists (Dennis, Trieschmann, Northcraft, \& Niemi, 2002; Im, Kim, \& Kim, 1998), and the previous analysis was run against that subset to see if faculty at top research schools had a different teaching vs. research profile.

The results are presented in Table 2 . What they show is that, overall, only $27 \%$ of all faculty members had any overlap between their teaching areas and research interests, with faculty reporting research interests directly related to any teaching area being about half of that . Moreover, when broken down by MIS research schools, the overlap for those in top schools fell to $24 \%$.

Table 2: Research Interest versus Teaching Area Comparison

\begin{tabular}{|c|c|c|c|c|}
\hline & All & Direct & $\begin{array}{l}\text { Indirect } \\
\text { Only }\end{array}$ & None \\
\hline Programming & 915 & 36 & 89 & 790 \\
\hline Percentages & & $4 \%$ & $10 \%$ & $86 \%$ \\
\hline Databases & 683 & 115 & 81 & 487 \\
\hline Percentages & & $17 \%$ & $12 \%$ & $71 \%$ \\
\hline Data Communications & 818 & 124 & 227 & 467 \\
\hline Percentages & & $15 \%$ & $28 \%$ & $57 \%$ \\
\hline Analysis and Design & 1143 & 205 & 182 & 756 \\
\hline Percentages & & $18 \%$ & $16 \%$ & $66 \%$ \\
\hline All & 2361 & 337 & 290 & 1734 \\
\hline $\begin{array}{rr}\text { Percentages } \\
\end{array}$ & & $14 \%$ & $12 \%$ & $73 \%$ \\
\hline All - Top MIS Schools - Multiple Sources & 491 & 62 & 56 & 373 \\
\hline $\begin{array}{ll} & \text { Percentages } \\
\end{array}$ & & $13 \%$ & $11 \%$ & $76 \%$ \\
\hline Excluding Top MIS Schools & 1870 & 275 & 234 & 1361 \\
\hline Percentages & & $15 \%$ & $13 \%$ & $73 \%$ \\
\hline
\end{tabular}

Naturally, considerable care should be taken in interpreting these results. First, because the data are not longitudinal, they tell us nothing about whether or not the overlap between teaching and research is growing or shrinking. Second, there is nothing in these results that should be taken as implying that the faculty with no overlap between teaching areas and research interests are not knowledgeable and effective teachers. Rather, it suggests that those activities they engage in to enhance their teaching-related knowledge might best be characterized as being part of the institutional informing system (which is heavily oriented towards fulfilling the requirements of student clients), rather than as part of the disciplinary informing system (which is more focused on knowledge creation research activities). It further calls into question the notion, sometimes advanced, that research universities benefit students by giving them the opportunity to see cutting edge MIS research brought into the classroom.

As was the case for practitioner research, another potential indication of the priority given to students clients by the discipline is the degree of importance accorded to SOT/ancillary research. As noted previously, such research differs from other types of applied research in that it may (or may not) employ similar reference disciplines as the pure and applied research of the field itself. In the 
case of MIS, the overlap between pure and SOT disciplines is fairly strong since the MIS area is currently dominated by behavioral research (Hevner, et al. 2004) and because information technology is having a strong impact on education - making it an appropriate field for applied MIS research. Here, however, the situation is even bleaker than was the case for practitioner-based research. The top ranked MIS journal focused on teaching, the Journal of IS Education, ranks $80^{\text {th }}$ on the AIS composite list.

From these observations, we may conclude that the MIS discipline's focus on its student clients is limited. Once again, we do not take this to imply that MIS faculty members are not enthusiastically serving the needs of student clients. Rather, we suggest that such service is best characterized as an institutional, rather than a disciplinary, priority. Stated another way, the discipline's principal informing activities are not directed towards student clients.

One remaining set of possible clients that warrants consideration is other disciplines. Indeed, there has been an argument made that MIS should serve as a reference discipline for other fields (Baskerville \& Meyers, 2002). At the same time, those authors state:

Since IS was defined early on as an applied discipline, the conventional wisdom has held that our research is targeted primarily at IS researchers and practitioners - indeed, many IS journals explicitly require authors to discuss the implications of their work for these two audiences. That our research might be of interest to researchers or practitioners in other fields seems not to have been considered. (p. 1)

Citation analysis seems to support the view that MIS research is presently doing little to inform other business disciplines. In a study of out-of-field citations among top journals (Wade, Biehl, \& Kim, 2006), MIS scored near the bottom (just ahead of ethics) with 0.19 out-of-field citations per article (for comparison purposes, General Management averaged 5.03, Organizational Behavior scored 1.96 and Finance scored 1.30; p. 254). Furthermore, the same research found that nonMIS citations to MIS articles have been dropping over time (since their peak in 1997), with external citations as a percentage of citable articles dropping even faster, since 1992 (p. 259). The situation appears even worse when MIS is contrasted with International Business - another relatively young discipline - where outside citations have risen materially during the same period (p. 260).

Having provided evidence that practitioners, students and other disciplines serve a very limited role as clients in the MIS informing system, the question remains: Who is MIS informing? The obvious answer is other members of the MIS discipline. In other words, nearly all informing activity is directed towards pure research (i.e., enhancing the informing environment). There are a number of reasons for believing this to be the case:

1. All available MIS departmental rankings appear to be based strictly on publications in a small number of MIS research journals

2. MIS departments are relying heavily on metrics such as journal impact factor in assessing individual research contribution. It would be hard to devise a metric better constructed to reward pure research activities.

3. The field is continually trying to determine what is and what is not MIS (e.g., Agarwal \& Lucas, 2005; Benbasat \& Zmud, 2003; Hevner, March, Park, \& Ram, 2004). In a discipline with clearly identified clients, the needs of the task completion system would determine what was, and was not, an appropriate set of problems to address.

4. Despite frequent calls for a re-evaluation of priorities (e.g., Benbasat \& Zmud, 1999; Davenport \& Markus, 1999), the discipline's research continually gravitates towards emphasizing rigor (a measure of logical quality control in the sender's informing environ- 
ment) over relevance (the degree to which research findings are likely to impact the client's task completion environment).

5. As suggested by the earlier Figure 4, faculty members tend to have some discretion with respect to their level of participation in the institutional and disciplinary informing system. Incentives for individual faculty, however, are strongly biased towards active participation in the disciplinary informing system. Specifically, the two most effective ways of increasing an MIS faculty member's compensation are to publish in refereed journals and to change institutions (Gill, 2001). Both of these tend increase the individual's motivation to participate in pure research aimed at top-ranked MIS journals. The latter tends to undermine loyalty to the institution, as well.

Thus, evidence clearly points to a conclusion that the principal role of the MIS disciplinary informing system is, at the present time, to inform itself.

\section{An Unpleasant Scenario for the Future of MIS Research}

So what are the implications of a discipline that, after more than 30 years, still mainly focuses on informing itself? Ironically, the short run implications for active participants in the discipline may seem mainly positive. Specifically, dramatically reduced enrollments lead to smaller classes, on average, and make it easier to make a case for reducing teaching load in favor of increased research assignments. Since, during its bubble years, MIS was frequently criticized for its excessive reliance on adjuncts and instructors, those temporary faculty - who were never active participants in the disciplinary informing system - are the ones most likely to experience layoffs. Furthermore, external requirements on the institution (e.g., new accreditation requirements that MIS be incorporated into the business curriculum) ensure that some new MIS teaching opportunities will be created, perhaps even enough to find placements for faculty displaced by the overall shrinkage in student demand. The group that has the most to lose during this period is the doctoral students. A relatively small number of these will be able to find positions at research schools; far fewer still will be able to meet the requirements for tenure (Dennis et al., 2006). To borrow a phrase used to describe junior faculty at Harvard, they will be like victims of a terminal disease - treated with great compassion but with the unspoken understanding that they won't be around for very long.

Barring a major rebounding in student enrollment - an external effect that would invalidate this entire scenario - the medium term is likely to bring substantially more pain to the typical participant in the research discipline. Given that student demand doesn't drive institutional motivation to supply resources to MIS departments, institutions would seem to have two choices. The first would be to starve the departments. There would be very little danger that faculty would leave during extended periods of contraction. Furthermore, even if they were to leave, there are few MIS courses that could not be outsourced to other disciplines (e.g., accounting information systems, engineering, computer science, management).

As a second strategy, some institutions could use MIS as a means of increasing their overall ranking as research schools. The reasoning here is as follows. At the very top schools, if MIS is not serving any useful external clients, they can simply starve the department for resources and their faculty will tend to move elsewhere. That creates an opportunity for less highly ranked schools to acquire a stellar faculty - probably more easily than would be the case for any other discipline. Doing so could meet the institution's needs for informing its "ranking" clients which, in turn, inform other constituencies (e.g., students, benefactors). In effect, MIS becomes the low hanging fruit. Some tantalizing evidence that such a process may already be taking place can be found in the 2001 ranking of business research areas (Dennis et al., 2002). The top 10 of these are shown in Table 3. 
What is surprising about these ratings is the degree to which extremely highly rated private schools, with large endowments, have MIS departments with very low ratings (e.g., $37^{\text {th }}$ at Wharton, $18^{\text {th }}$ at Harvard, $45^{\text {th }}$ at Stanford, not even present at Chicago). Further supporting the trend is the fact that every school with a top ten MIS program in the top 10 schools also experienced a rise in overall ratings. For two of the schools (UNC Chapel Hill and Indiana, the jump was substantial). A reasonable speculation would therefore be that acquiring a strong MIS research faculty could be part of a concerted effort to move up the rankings. Also interesting is the fact that the only other discipline where a similar pattern occurs is in POM (production and operations management), which experienced at similar drop in interest a few decades ago (largely as a result of U.S. manufacturing's move off shore), and has already been absorbed by other departments at many institutions.

Table 3: Rankings by discipline from Dennis, et al (2002)

\begin{tabular}{|c|c|c|c|c|c|c|c|c|c|c|c|}
\hline $\begin{array}{l}\text { Rank } \\
1997- \\
2001\end{array}$ & $\begin{array}{c}\text { Rank } \\
1986- \\
1998\end{array}$ & $\begin{array}{l}\text { Percent } \\
\text { of } \\
\text { Pages }\end{array}$ & University & $\begin{array}{l}\text { } \\
\delta \\
\delta \\
\text { 音. } \\
\text { 音 }\end{array}$ & 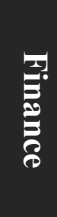 & $\begin{array}{l}\bar{\Xi} \\
\overline{0} \\
\overline{0}\end{array}$ & 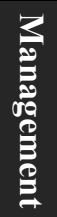 & 3 & 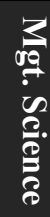 & 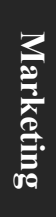 & $\begin{array}{l}7 \\
8 \\
3\end{array}$ \\
\hline 1 & 1 & $3.96 \%$ & Pennsylvania & 1 & 2 & 1 & 4 & 37 & 2 & 1 & 63 \\
\hline 2 & 2 & $2.58 \%$ & Michigan & 7 & 14 & 10 & 1 & 14 & 7 & 13 & 8 \\
\hline 3 & 9 & $2.56 \%$ & Harvard & 9 & 3 & 12 & 11 & 18 & 11 & 8 & 49 \\
\hline 4 & 3 & $2.51 \%$ & Stanford & 4 & 9 & 69 & 7 & 45 & 5 & 15 & \\
\hline 5 & 5 & $2.49 \%$ & Chicago & 3 & 1 & 35 & 37 & & 24 & 14 & \\
\hline 6 & 23 & $2.41 \%$ & $\begin{array}{l}\text { UNC - Chapel } \\
\text { Hill }\end{array}$ & 2 & 11 & 28 & 17 & 9 & 32 & 31 & 9 \\
\hline 7 & 8 & $2.32 \%$ & Texas - Austin & 12 & 12 & 7 & 5 & 7 & 9 & 4 & 95 \\
\hline 8 & 10 & $2.32 \%$ & Northwestern & 5 & 10 & & 6 & & 8 & 12 & \\
\hline 9 & 6 & $2.17 \%$ & Columbia & 10 & 8 & 41 & 14 & & 1 & 3 & \\
\hline 10 & 21 & $1.92 \%$ & Indiana & 8 & 46 & 36 & 16 & 2 & 55 & 18 & 90 \\
\hline
\end{tabular}

The problem with institutions using MIS as a means of elevating their rankings is that the approach will only work at a limited number of sites. An institution would need an MIS area far higher than its overall research average to produce a worthwhile ratings impact. In addition, as more and more highly ranked institutions come to view MIS as a disciplinary pariah, the weight it is given in research rankings, along with the accompanying impact, is likely to decline. During this period, MIS researchers would therefore be motivated to further integrate their research with that of other disciplines - increasing their individual respectability but further eroding the justification for the existence of a separate MIS informing system.

If MIS does not change direction and make a concerted effort to find external clients in the near future, the long term prognosis for the MIS discipline would seem to be very grim. MIS departments are likely to shrink and then, finally, be absorbed by other departments at nearly all institutions - much the way management science and production/operations management have already been. Although MIS research will doubtless continue to exist, it will do so at the forbearance of other disciplines. Without departments - the instance construction engine of the informing system - there will be far fewer doctoral students. That will, in turn, lead to a shrinking of research output and a graying of the professoriate. What participants remain in the system a few decades hence will doubtless look back to the late 1990s as "the good old days" unless radical changes happen soon. 


\section{Clients for the Informing Sciences}

The purpose of presenting the MIS case study was twofold. First, it illustrates the power of the informing sciences lens in analyzing complex systems. Second, it should be viewed as a cautionary tale. As illustrated by the earlier Table 1, MIS started as a partnership between academia and industry clients, and was later fueled by skyrocketing demand from student clients. We have proposed that it is only through ignoring these clients that it reached its current perilous condition.

The informing sciences were started with neither a practitioner base nor a student base to work with. It is, therefore, high time for the discipline to "eat its own dog food" (a phrase used by both Microsoft and Sun to describe using the same technologies that they sell to their customers for the purposes of running their internal systems) and apply the informing sciences framework to analyzing its own situation. Specifically, it is time to identify the specific types of external clients that are to be informed in the future.

\section{Criteria for Identifying Plausible Clients}

As implied by the previous discussion of the MIS disciplinary informing system, identifying and committing to serve specific clients greatly reduces a discipline's need for introspective (and interminable) discussions regarding what does and what does not constitute valid disciplinary research. The informing science framework, however, suggests that not all clients are created equal. Specifically, we propose that at least four criteria must be met for a client to be considered ideal:

- The client has an unaddressed set of problems: Just as the MIS field emerged as a separate discipline largely as a consequence of the software crisis of the late 1960s and early 1970 s, clients with serious issues not currently being effectively addressed by other disciplines will tend to exhibit the greatest receptivity to new perspectives.

- Serving the client provides access to resources: Unless the members of a discipline have unlimited financial resources, a condition that is highly unlikely, the ideal client can provide access to needed resources in two ways. First, it could supply resources to the discipline directly in return for informing activities (e.g., through consulting fees or grants). Second, it can be a significant client of the institutional informing system, in which case fulfilling the client's need provides a justification for acquiring a share of institutional resources.

- $\quad$ The members of the discipline have the expertise to address the client's unaddressed problems: Just because a potential client has significant unaddressed problems does not necessarily mean that any sender can be effective in addressing them. An interesting example of this is the recent call for the MIS to place greater focus on design research (Hevner et al., 2004). The researchers make a compelling case for the need for such research and also identify suitable clients for the research. The greatest challenge presented by the proposal can be illustrated using the researchers' own words: "The primary goal of this paper is to inform the community of IS researchers and practitioners of how to conduct, evaluate, and present design science research" (p. 77). What is the likelihood that the members of a discipline that has become dominated by a behavior approach to research (as asserted by the researchers themselves) will have the skills required to embark on a totally different research agenda? And, if they do not have those skills at present, how long will it take to acquire them?

- One or more resonant communications channels exist, or can be created: Some means of moving information from the discipline to the client must be present if the system is to inform. The use of the term resonance is intended to imply amplification of the message as it moves through the channel (e.g., as an instrument amplifies the sound produced by a 
vibrating string) and further amplification as it reaches the client (e.g., as a well-designed concert hall enhances, rather than deadens, the sound).

The last of these criteria warrants some additional comment. As noted in the MIS example, a discipline often views its research in terms of a tradeoff between rigor (assessed at the sender-side informing environment) and relevance (related to the client-side task completion system). In informing system terms, however, this ignores an important part of the system - the channel. We believe, therefore, that the criteria for judging effective research need to be augmented with a third dimension that defines the ability of that research to bridge the divide between sender and client. In Shannon's (Shannon \& Weaver, 1949) terms, this characteristic - which we refer to as resonance (both because it conveys the proper image and because it alliterates with the other two terms really well) - is particularly focused on how the message is encoded, the transmission medium, and how it is decoded in a form that is appropriate for inducing changes in client activities. An additional aspect of resonance is the degree to which secondary informing activities (sympathetic vibrations in physical terms, "word-of-mouth" in a business context) are invoked within the client's internal systems. Some MIS discussions of rigor versus relevance view resonance as an element of relevance (e.g., by including publication outlet as part of the debate, as in Davenport \& Markus; 1999). Others view outlet as less important than the need to better train practitioners to read MIS research in its unabridged form (e.g., Lyytinen, 1999). We believe that both perspectives ignore the power of resonant messages, even in the absence of rigor or relevance. To use a U.S.-specific example, consider the power of college athletics - particularly football and basketball-as a means of communicating with various institutional client constituencies (e.g., potential students, alumni, benefactors, legislators, etc.) Although the precise role that fielding championship football teams plays in fostering research and informing students is obscure, the resonance that such a team can produce within the institution's client base could well justify the massive injection of resources that developing such a program requires. For example, few casual observers would guess that the authors' own institution, University of South Florida, has both a substantially larger student body and substantially more external funding than its northern neighbor, Florida State University. Where the latter has a huge advantage, however, is in its long-standing ability to field football teams that are nationally competitive. Viewed in the context of informing resonance, it makes perfect sense that the football coach — not the president or the most eminent professor - tends to be the most highly paid individual at such institutions.

\section{Examples of Plausible Informing Science Clients}

To illustrate how the above criteria might be applied, it is useful to propose some examples of clients - inspired by the analysis of the present paper - that might fit well into the portfolio of clients that the informing science discipline serves.

\section{Distance learning educators and administrators}

The topic area of distance learning has been studied extensively, both in the field of education and in the disciplines that employ it. Despite this fact, opinions on the subject that are nearly polar opposites persist (e.g., Hirshheim, 2005; Gill, 2006) and myths abound (Sarker \& Nicholson, 2005). One likely explanation for the lack of consensus is that the establishment of distance learning programs invariably involves the interaction between disciplinary and institutional informing systems. What is particularly intriguing about this area, however, is that polar opposite positions exist within both informing systems. For examples, some administrators may strongly support distance learning adoption for reasons of achieving cost savings, to leverage scarce facilities and/or to meet the needs of working student clients. On the other hand, they may resist it on the basis that it will lead to the perception - amongst employer and rating clients - that the institution is opportunistically ushering in reduced standards. Disciplinary participants, on the other hand, 
may condemn it for its impact on their rhythm of life, for reducing the richness of their interactions with students, for the extra work it entails, and/or for the difficulty in maintaining quality control in assessments. Other faculty members, however, may see it favorably through the lens of how it increases the range of content and experiences that can provide to students and the increased time/place flexibility it gives them in their personal and research activities.

The study of distance learning from the informing science perspective would be a good fit with the plausible client criteria. Specifically:

- As already noted, there exists a wide range of opinions regarding both the educational effectiveness and institutional desirability of distance learning, and little evidence that a consensus is forming. Furthermore, implementation of such programs requires substantial coordination between disciplinary and institutional informing systems, as well as the deployment of substantial technical infrastructure. The large number of participating systems suggests that a single discipline (e.g., education) is less likely to be able to address the entire problem than a transdisciplinary approach. Indeed, a plausible explanation for the existing lack of consensus on the subject is that, too often, it is being approached from a single disciplinary perspective.

- Inasmuch as the institutional informing system would be a major beneficiary of advances in this area, it is reasonable to suppose that such research would be viewed as worthy of some allocation of institutional resources.

- Within the informing sciences transdiscipline there already exists the appropriate balance of expertise, with educational (e.g., education, library science), managerial (e.g., MIS) and technological (e.g., computer science, instructional technology) perspectives all being well represented.

- With faculty and institutional administration being the clients, existing channels (e.g., articles in scholarly journals) may be effective in producing resonance-indeed, the academic clientele is one of the few for whom such outlets resonate. Furthermore, the Informing Science Institute already publishes a number of journals directly (e.g., Interdisciplinary Journal of Knowledge and Learning Objects) or somewhat (e.g., Journal of Information Technology Education, Issues in Informing Science and Information Technology Journal) related to the subject area.

\section{Disciplinary and institutional leadership}

A similar clientele, albeit at a somewhat higher level, would involve the leadership of the various disciplines and academic institutions. As illustrated by the present paper, academic institutions face a major challenge is determining how to allocate resources between disciplinary informing systems. Similarly, we can easily locate complaints about incomprehensible administrative priorities that are voiced by faculty members - just look at any faculty union newsletter. Although studying the interaction between these systems would be something of a departure from informing science's roots as an alternative perspective on MIS, the only type of research program that would have any chance of being effective in servicing this clientele would have to be transdisciplinary in nature. To what extent would a college of engineering be agreeable to priorities established by the educational leadership discipline (situated within the college of education) or the sociology discipline (within arts and sciences)?

In some respects, the study of disciplinary-institutional interactions fits a similar plausibility profile to that of distance learning. Specifically:

- The problem of allocating academic resources is increasingly being recognized. Since the early 1980s, the cost of a higher education has been increasing faster than almost any 
other category of goods or services (including medicine), with college costs increases outpacing family income growth by a factor of three (Boehner, 2003). The long term consequence of this trend is likely to be the need for substantially greater institutional cost containment measures than are currently in place, creating a greater need for prioritizing support to disciplines.

- Once again, with the institutional informing system being a major beneficiary of advances in this area, it should be deemed resource-worthy.

Other areas of fit are somewhat less compelling. On the other hand, it is hard to identify any other discipline or transdiscipline that is currently better positioned for investigations in this area. For example:

- In additional to the business, communication, library science and education disciplines, participants in the informing sciences also include members of many other disciplines, such as liberal arts and engineering. Of particular note, philosophy-likely to be a key element of any investigations - is already represented in contributions to the Informing Science Journal and related journals (e.g. Gackowski, 2006; Mende, 2005).

- Although faculty and institutional clients can, to some degree, be served by traditional journal articles, as the range of disciplinary clientele being served grows, so must the range of channels that are to be used. Scholarly monographs (not collections of loosely related articles bound in book form), that are largely discounted by some disciplines carry the greatest weight in others. Electronic publications are acceptable in some areas and deemed entirely inappropriate for others. Case studies are applauded in some areas, reviled for being non-rigorous by others. Technology-based artifacts may be treated as the ultimate proof of concept by one group and may intimidate or alienate another. While recognizing that the informing sciences has a distance to go in supporting the full range of channels necessary, it is also reasonable to celebrate how far it has come. For example, the Informing Science Institute (ISI) currently supports both electronic and print formats for all its journals and books. ISI is also developing repositories suitable for technological artifacts (e.g., the Teach IS site at http://teachis.org ). Over the past year, it has launched two new journal specifically directed at a clientele of faculty and doctoral students across all disciplines, one being a traditional journal (Journal of Doctoral Studies), one publishing case studies (Informing Faculty). Thus, while progress must (naturally) continue, there are few organizations currently better positioned to inform the diversity of clients in this research domain.

Before leaving the subject of plausible clients we must emphasize, once again, that the examples being presented are not intended to identify the appropriate clients for the informing sciences. Rather, they are presented to illustrate the type of analysis that could be determined in assessing the appropriateness of a possible client and to suggest possible candidates for inclusion in what will undoubtedly be a portfolio of informing science clients.

\section{Complex Systems: A Transdiscipline Success Story}

In addition to identifying plausible clients, participants in the informing science discipline might do well to consider the experiences of other transdisciplines that have effectively navigated the pitfalls of establishing a new informing system. One example that immediately springs to mind is the study of complex systems (sometimes also referred to as complex adaptive systems). The underlying premise of this discipline - much like that of the informing sciences - is that certain types of systems (incorporating many interconnected elements that interact with each other) begin to exhibit certain characteristics (e.g., punctuated equilibrium; Bak, 1996) regardless of the context in which they were observed. Where that discipline differs most markedly from the inform- 
ing sciences is that their focus is on the behavior as the system as a whole, whereas the informing sciences focuses on the behavior of coupled sender and client systems.

Over a period of less than a decade after its inception, the complex systems transdisciplinewhich incorporates fields as diverse as biology, geology, physics, engineering, computer science, economics and sociology - had established itself as an important research area. Some of the techniques employed by the field have been chronicled in popular accounts (e.g., Waldrop, 1992):

- The research problem to be addressed was defined as identifying and understanding emergent behaviors of systems that consist on many elements that interact with each other. The early participants further decided that quantitative and algorithmic approaches to defining such systems would be targeted, as opposed to qualitative, interpretive techniques.

- The targeted clients were researchers in other disciplines addressing problems of intractable system behavior, e.g., understanding earthquakes and volcanoes in geology, understanding economic turbulence in business and economics, understanding major climate shifts in climatology, understanding sudden evolutionary transitions in biology, understanding the behavior of cellular automata, neural networks and genetic algorithms in computer science, etc. Because such problems tended to be the most intractable ones in their respective disciplines, the receptivity of researchers to alternative solutions tended to be high.

- The early participants in the field established an umbrella organization, the Santa Fe Institute, to help guide the evolution of the field. That institute sponsored conferences as a means of informing new participants. These conferences, in turn, included extensive workshops intended to ensure that participants from very different disciplines became acquainted with the mathematical and algorithmic disciplinary paradigms.

- Participants made an active effort to inform and recruit researchers from many fields who appeared to be examining the types of problems that were the focus of the complex systems transdiscipline

- Individual participants published books that were specifically written to appeal to the general reader (e.g., Bak, 1996; Gell-Mann, 1994; Kauffman, 1995; Prigogine, 1997), and supported journalistic authors in their efforts to catalog the field (e.g. Waldrop, 1992).

As a result of these efforts, the complex system transdiscipline achieved widespread legitimacy as a research area. Moreover, participation in the field further enhanced the prestige and recognition accorded to individual researchers. Much of this can be attributed to the transdiscipline's selection of a set of clients (researchers across related disciplines) with genuine problems to address (understanding the behaviors of systems that were largely intractable) and developing channels appropriate for communicating with these clients (e.g., workshops, books accessible to readers outside of the author's discipline). In addition, through its support of channels intended to resonate with general interest readers, it also helped ensure that institutions would perceive that having ongoing research in complex systems would be a benefit to their own external clientele.

Naturally, there were many additional factors that fueled the success of the complex systems transdiscipline. In establishing credibility, for example, it never hurts to have several Nobel laureates amongst your initial participants. Nonetheless, it is definitely worth noting that many of the activities that contributed to the success of complex systems were never systematically undertaken by the MIS discipline. Among these, identifying a clear client/problem-to-be-solved pairing, actively encouraging the dissemination of research into other disciplines (the very antithesis of judging research success solely in terms of publication counts in a discipline specific set of 
"elite" journals), and valuing the publication of less technical works (e.g., books) intended to spread knowledge of the discipline to external communities - recognizing that these would, in turn, be valued by the institutions that provided participants with most of their resources. In short, the complex systems transdiscipline paid careful attention to their external clients, and to ensuring that their communications were resonant.

\section{Implications for the Informing Sciences}

The greatest danger that an academic discipline can face is the belief that resonant communications within the discipline are sufficient to justify its existence as an informing system. We have argued that MIS is currently paying the price for such hubris. The informing sciences transdiscipline, however, is not immune from the same peril. Being younger however, and much less accustomed to free flowing resources - resources that, in MIS, were unleashed by a tide of students once thought to be inexhaustible - the informing sciences are in a much better position to avoid the trap.

There are a number of general propositions that this paper has advanced, derived from the use of the informing science framework in analyzing academic informing systems. These include:

- The appropriate research areas for a discipline are best determined by the clients it serves. Continual debates regarding what is and is not appropriate research within the discipline is clear evidence of a shortage of external clients.

- Resonance is the degree to which the information being conveyed is of a form that can cross the sender/client boundary and produce secondary informing activities within the internal client system. If resonance is not present, communications from sender to client will be severely attenuated, if not lost entirely. Without knowing the client, predicting resonant communication forms is impossible.

- The dimensions of rigor and relevance are, by themselves, insufficient to ensure effective research. Instead, rigor, relevance and resonance must all be achieved if research is to have impact.

- Academic informing systems typically come in disciplinary-institutional pairs, with the former determining research directions and the latter prioritizing resources. These pairs typically share some common elements on both the sender (e.g., faculty, departments) and client (e.g., students, practitioners) side. In the absence strong external clients, individual faculty at research institutions will tend to be drawn towards greater participation in the disciplinary system - which offers great incentives for research success - while departments and colleges will be drawn towards greater participation in the institutional systems, where greater opportunities for advancement in the institutional resource queue are likely to be found.

- A discipline's long term success at a given institution depends upon the degree to which its clients overlap with the institution's clients, since that will tend to determine its priority in the queue for institutional resources.

- A transdiscipline can be described as an informing system that takes a particular problem or scenario and examines it across many disciplines. For this reason, the natural client of the informing sciences is other disciplines. Nonetheless, if it is to survive over the longterm, the informing sciences will still need to find ways of serving clients who are also institutional clients.

If the informing sciences were to look to another transdiscipline as a model for best practices, the study of complex systems would be a good candidate. The two transdisciplines exhibit similari- 
ties across several important dimensions. They both were established to study a particular type of system behavior (i.e., emergent behaviors of systems with many interacting components, activities of sender-client pairs). They both employ an institute to help initiate and coordinate disciplinary activities (i.e., Santa Fe Institute, Informing Science Institute). They both welcome participation from a range of disciplines far broader than would normally be encountered in academic circles. They both encourage a broad range of publication types. There are, however, some activities performed by complex systems that the informing sciences has yet to engage in, but might seriously consider emulating:

- Establishing a catalog of resonant exemplars. When one thinks of the complex systems discipline, one thinks of Bak's sand piles, Wolfram's cellular automata, Holland's genetic algorithms, Kauffman's fitness topology (with its the pre-Cambrian explosion), along with many other compelling examples. If the informing sciences transdiscipline is to thrive, it needs its own set of exemplars that both illustrate why it is sensible to study such systems collectively and why there is a pressing need to do so.

- Educate participants with respect to the nature of the informing sciences. One of the pitfalls of bringing many disciplines together (as well with being the greatest source of value!) is that each needs to be educated with respect to the frame of reference of the others. At its conferences, the Santa Fe Institute sponsors an extensive series of tutorial workshops intended to instruct participants in the basics, and non-so-basics, of complex systems research. A similar set of workshops should be hosted at InSITE conferences if the transdisciplinary mission is to be accomplished.

- Encourage more resonant publications. Relatively few significant advances in complex systems were not accompanied by books or articles that were written so as to stimulate the popular imagination. While such activities tend to produce reactions of disdain amongst many serious academics, they play a particularly important role in a transdiscipline: as the means of communicating findings to those researchers in other disciplines who could never be expected to read anything written in the formal academic prose favored by the disciplines of the original authors. This also means attempting to develop a portfolio of publication types, since what leads to resonance in one discipline may not even make it past the client/sender barrier in another.

- Place a premium on informing science framework usage outside of Informing Science Institute (ISI) publications. Editors and reviewers of Informing Science Journal have, in the past, been advised to encourage authors to submit their best work to that journal. Paradoxically, what is obviously in the best interest of the journal over the short term may be the worst possible advice to give over the long term. If a manuscript is really good, and if it explicitly applies the informing science framework to another discipline, then the best place for it would be in a premier disciplinary journal. Acceptance and publication in such an outlet would, all at once: 1) elevate the profile of the informing sciences within that discipline, 2) familiarize researchers considering problems falling under the category of informing systems of the transdiscipline's existence, and 3) provide an example of the transdiscipline informing an external client (in this case, the discipline publishing the research).

- Become more proactive in identifying potential participants. A central tenet of the Informing Science family of journals has always been to welcome authors and provide mentoring to all participants. Where additional proactive efforts might pay great dividends is in identifying potential new participants through their research. Towards this end, it might make sense to approach certain authors (of high quality research involving client-sender situations already published in disciplinary outlets) with an invitation to 
write a revised version of their article for publication in Informing Science or some other appropriate outlet.

These types of activities could help enhance the effectiveness of the informing sciences in delivering its message to a broad set of clients. Such techniques, however, can only be effective if the clients are known. Identifying external clients, we believe, is the essential next step for the transdiscipline. The danger of postponing a systematic effort to identify such clients is that the informing sciences could end up pursuing the same path as MIS. And could be destined to experience what MIS is now experiencing.

\section{References}

Agarwal, R. \& Lucas, H. (2005). The information systems identity crisis: Focusing on high-visibility and high-impact research. MIS Quarterly, 29(3), 381-398.

Bak, P. (1996). How nature works: The science of self-organized criticality. New York: Springer Verlag.

Baskerville, R. \& Meyers, M. (2002). Information systems as a reference discipline. MIS Quarterly, 26(1), $1-14$.

Benbasat, I. \& Zmud, R. (1999). Empirical research in information systems: The practice of relevance. MIS Quarterly, 23(1), 3-16.

Benbasat, I. \& Zmud, R. (2003). The identity crisis within the IS discipline: Defining and communicating the discipline's core properties. MIS Quarterly, 27(2), 183-194.

Boehner, J. (2003). The skyrocketing cost of higher education. Fact sheet prepared by U.S. House Education \& the Workforce Committee on 10 October 2003. Retrieved on 28 November 2006 from http://www.house.gov/ed_workforce/issues/108th/education/highereducation/factsheetcost101003.htm

Cohen, E. (1997). IS as an evolving field. In N. Callaos, C. M. Khoong, \& E. Cohen (Eds.), Proceedings of the World Multiconference on Systemics, Cybernetics, and Informatics, Caracas, Venezuela, July 7-11 1997.

Cohen, E. (1999). Reconceptualizing information systems as a field of the transdiscipline informing science: From ugly duckling to swan. Journal of Computing and Information Technology, 7(3), 213-219.

Davenport, T. \& Markus, M. L.. (1999). Rigor vs. relevance revisited: Response to Benbasat and Zmud. MIS Quarterly, 23(1), 19-23.

Davis, G., Gorgone, J., Couger, J. T., Feinstein, D, \& Logenecker, H. (1997). Model curriculum and guidelines for undergraduate degree programs in information systems. AITP.

Dennis, A., Trieschmann, J., Northcraft, G. \& Niemi Jr., A. (2002). Business school research performance: An update. Retrieved 15 November 2006 from http://www.kelley.iu.edu/ardennis/rankings/rank2001.doc

Dennis, A., Valacich, J., Fuller, M. \& Schneider, C. (2006). Research standards for promotion and tenure in information systems. MIS Quarterly, 30(1), 1-12

Drucker, P. (1989). The new realities. New York: Harper \& Row.

Dubé, L. \& Paré, G. (2003). Rigor in information systems positivist case research: Current practices, trends, and recommendations. MIS Quarterly, 27(4), 597-635.

Freeman, L., Jarvenpaa, S. \& Wheeler, B. (2000). The supply and demand of information systems doctorates: Past, present, and future. MIS Quarterly, 24(3), 355-380.

Gackowski, Z. (2006). Quality of informing: Bias and disinformation philosophical background and roots. Issues in Informing Science and Information Technology, 3, 731-744. Available at http://informingscience.org/proceedings/InSITE2006/IISITZbig250.pdf

Gell-Mann, M. (1994). The quark and the jaguar. New York: Free Press. 
George, J., Valacich, J. \& Valor, J. (2004). Does information systems still matter? Lessons for a maturing discipline. Twenty-Fifth International Conference on Information Systems, 1039-1048.

Gill, T.G. (1995). High tech hidebound: Case studies of information technologies that inhibited organizational learning. Accounting, Management. \& Information Technology, 5(1), 41-60.

Gill, T.G. (2001). What's an MIS paper worth? (An exploratory analysis). Database for Advances in Information Systems, 32(2), 14-33.

Gill, T.G. (2006). 13 (educational) things I'd rather do over the Internet. eLearn, 32. Retrieved from http://www.elearnmag.org/subpage.cfm? section=articles\&article=32-1

Gregor, S. (2006). The nature of theory in information systems. MIS Quarterly, 30(3), 611-642.

Hevner, A., March, S., Park, J. \& Ram, S. (2004). Design science in information systems research. MIS Quarterly, 28(1), 75-105.

Hirshheim, R. (2005). The Internet-based education bandwagon: Look before you leap. Communications of the ACM, 48(7), 97-101.

Im, S., Kim, K. \& Kim, J. (1998). An assessment of individual and institutional research productivity in MIS. Decision Line, December/January.

Kauffman, S. (1995). At home in the universe. New York: Oxford University Press.

Lee, A. (1999). Rigor and relevance in MIS research: Beyond the approach of positivism alone. MIS Quarterly, 23(1), 31-33.

Lyytinen, K. (1999). Empirical research in information systems: On the relevance of practice in thinking of IS research. MIS Quarterly, 23(1), 25-28.

Mende, J. (2005). The poverty of empiricism. Informing Science Journal, 8, 189-210. Retrieved from http://inform.nu/Articles/Vol8/v8p189-210Mende.pdf

National Audit Office. (2006, November 17). Delivering successful IT-enabled business change. Report By The Comptroller And Auditor General (U.K.). HC 33-I Session 2006-2007.

Pfeffers, K \& Tang, Y. (2003). Identifying and evaluating the universe of outlets for information systems research: Ranking the journals. The Journal of Information Technology Theory and Application (JITTA), 5(1), 63-84.

Prigogine, I. (1997). The end of certainty. New York: Free Press.

Sarker. S. \& Nicholson, J. (2005). Exploring the myths about online education in information systems. Informing Science Journal, 8, 55-73. Retrieved from http://inform.nu/Articles/Vol8/v8p055073Sarker.pdf

Shannon, C. E. \& Weaver, W. (1949). The mathematical theory of communications. Urbana: University of Illinois Press.

Simon, H. (1981). The sciences of the artificial ( $2^{\text {nd }}$ ed.). Cambridge: MIT Press.

Swanson, E. B. \& Ramiller, N. C. (1993). Information systems research thematics: Submission to a new journal, 1987-1992. Information Systems Research, 4(4), 299-330.

Trieschmann, J., Dennis, A., Northcraft, G. \& Niemi Jr. A. (2000). Serving multiple constituencies in business schools: M.B.A. program versus research performance. Academy of Management Journal, 43(6), 1130-1141.

Wade, M., Biehl, M. \& Kim, H. (2006). Information systems is not a reference discipline (and what we can do about it). Journal of the Association for Information Systems, 7(5), 247-269

Waldrop, M. (1992). Complexity: The emerging science at the edge of chaos and order. New York: Simon and Schuster. 


\section{Biographies}

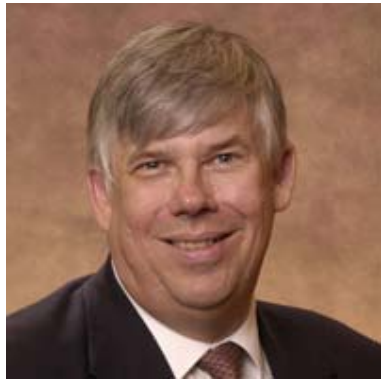

Grandon Gill is an Associate Professor in the Information Systems and Decision Sciences department at the University of South Florida. He holds a doctorate in Management Information Systems from Harvard Business School, where he also received his M.B.A. His current principal research focus is in the area of IS education, and he has published many articles describing how technologies and innovative pedagogies can be combined to increase the effectiveness of teaching across a broad range of IS topics. He is currently the Editor-In-Chief of Informing Faculty, is an Editor of the Journal of IT Education, and serves on the editorial boards of the Journal of IS Education and the Decision Sciences Journal of Innovative Education. Currently, he teaches programming, database and managerial courses to both undergraduate and graduate students.

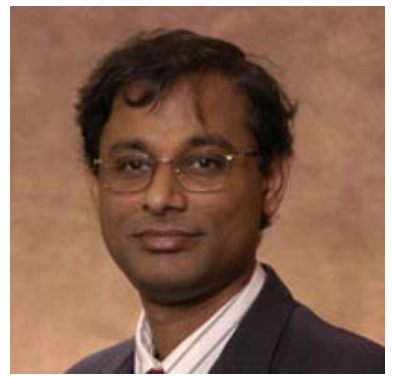

Anol Bhattacherjee is a tenured Associate Professor of Information Systems at the University of South Florida. He received his Ph.D and MBA degrees from University of Houston, and M.S. and B.S. degrees from Indian Institute of Technology (India). His primary areas of research are: (1) diffusion and use of information technology innovations, (2) applications of information technology in healthcare, and (3) knowledge transfer in social networks. His research has been published in eight of the top ten academic journals in the Information Systems discipline, including MIS Quarterly, Information Systems Research, Journal of MIS, and Decision Sciences. He currently serves in the editorial board of MIS Quarterly. Dr. Bhattacherjee teaches MBA and undergraduate classes in Electronic Commerce and a doctoral seminar in Research Methods. 